\title{
Numerical Analysis of Different Nose Shapes on the Train Aerodynamic Performance at a Windbreak Transition under Crosswinds
}

\author{
Zhengwei Chen, Tanghong Liu, Wenhui Li \\ Key Laboratory of Traffic Safety on Track of Ministry of Education, School of Traffic \& Transportation Engineering, Central \\ South University, Changsha, China \\ Email: gszxczw@csu.edu.cn, lth@csu.edu.cn,lwh@csu.edu.cn
}

How to cite this paper: Chen, Z.W., Liu, T.H. and Li, W.H. (2020) Numerical Analysis of Different Nose Shapes on the Train Aerodynamic Performance at a Windbreak Transition under Crosswinds. Journal of Applied Mathematics and Physics, 8, 2519-2525. https://doi.org/10.4236/jamp.2020.811187

Received: July 20, 2020

Accepted: November 23, 2020

Published: November 26, 2020

\begin{abstract}
Based on the Unsteady Reynolds-Averaged Navier-Stokes (URANS) method, this paper studied the effect of the nose shape on the aerodynamic performance when the high-speed train subjected to a windbreak transition under crosswinds. The windbreak transition generated by the irregular terrain from the flat ground to the cutting. The results showed that with the height of the front window increased from $Z-2$ to $Z+2$ (the dimensionless height), the side force coefficient $C_{y}$ and rolling moment coefficient $C_{m x}$ increased by $26 \%$ and $27 \%$ for the head car, respectively. The flow structures around the lower front window were smoother than that around the higher front window. The flow structures in the higher front window resulted in more considerable positive pressure on the windward side (WWS) and top of the nose region.
\end{abstract}

\section{Keywords}

Aerodynamics, High-Speed Train, Windbreak Transition, CFD

\section{Introduction}

The unsteady crosswind induced by different terrains and facilities beside the railway is a critical factor which affects the train aerodynamics performance [1], such as the transition region between the cutting and embankment, bridge and tunnel et al. [2] Under the crosswind, the windbreak is built based on its low cost and effectiveness. However, due to the change of terrains and facilities along the railway, so following the terrain, the windbreak is built discontinuously in some positions [3] [4]. For example, the Xinjiang railway in China was built in a 
strong wind area, and windbreaks were used frequently in this railway to reduce the safety risk of the train operation. Due to this railway passed through different landforms, which resulted in many cuttings, embankments and bridges et al. Under these circumstances, in the connection region between the flat ground/embankment and cutting, there was a right-angle irregular transition for the windbreak. The full-scale test showed that when the train passed through this windbreak transition region, there was a yawing motion and the train aerodynamic performance and vehicle system dynamic response occurred sudden changes, which influenced the passenger comforts and the train operation safety [5] [6] [7]. Generally, there are different methods to reduce the impact of this windbreak transition region, such as the limitation of train speed, optimisation of the connection structure. Meanwhile, for the train itself, the shape of the train can be considered to reduce the relative effects, too. In this paper, using the computational fluid dynamics (CFD) method, and considering different nose shapes of a train, the aerodynamic performances of the train under the windbreak transition were compared and determined the better shape of train nose under this windbreak transition region.

\section{Numerical Details}

\subsection{Model Description}

Figure 1 shows the computational model and its positions. The train located on the railway line-2 (RL-2). The railway line-1 (RL-1) is the one close to the windbreak wall. The train height $h$ was measured from the top of the rail (TOR) and was taken as the reference length. Similar to the wind tunnel test, the train was stationary and subjected to crosswind at $90^{\circ}$ yaw angle. Only the head car and a half of the second car were considered. Furthermore, the nose part of the train located in the region of windbreak transition. As shown in Figure 2, five different front window heights were studied in the present work. To compare conveniently, the dimensionless height of the front window, $\mathrm{Z} 0=1$, was taken as the reference value. With the other front window height decreased or increased,

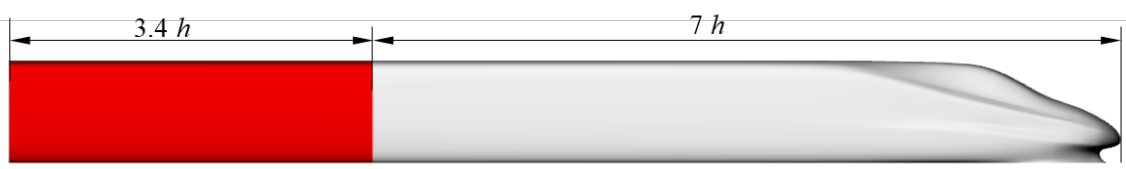

(a)

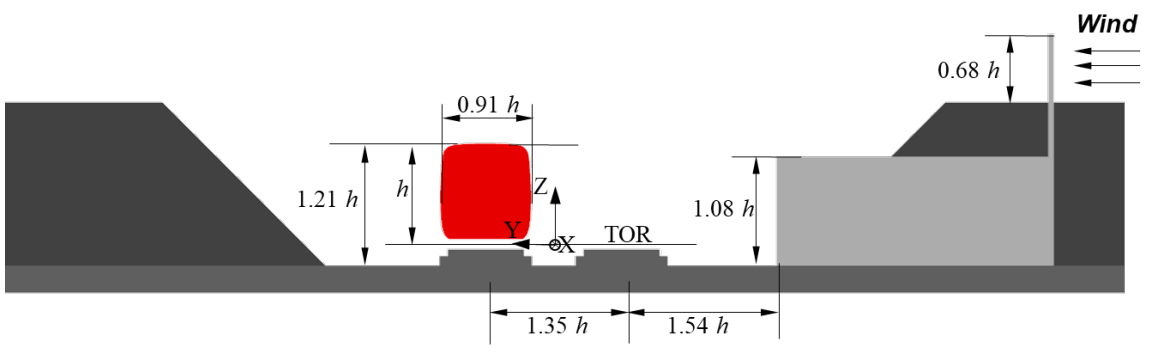

(b) 


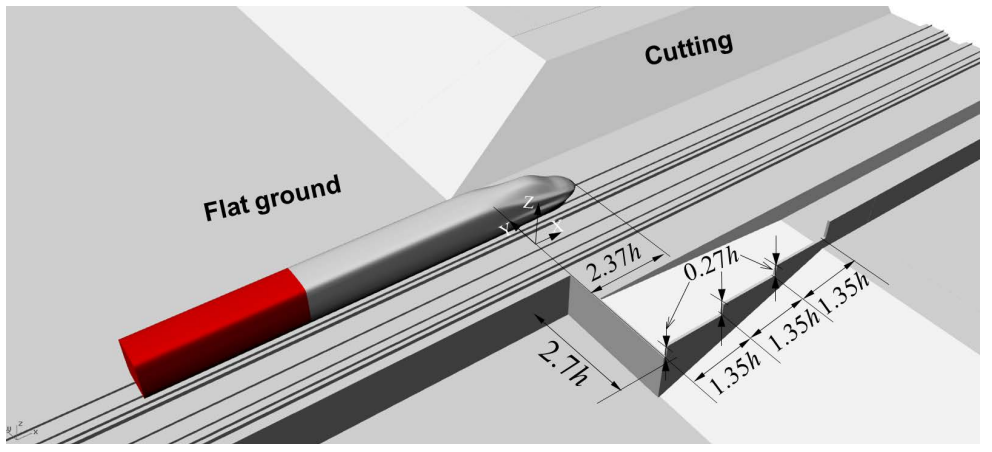

(c)

Figure 1. Computational models: (a) side view of the train, (b) front view and (c) three-dimensional view of the entire model.

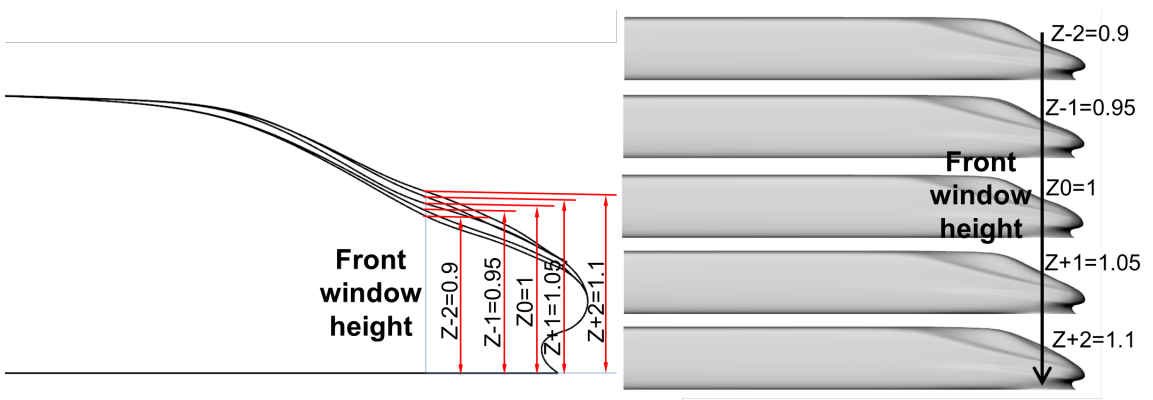

Figure 2. Different front window heights.

the corresponding shapes were named $Z-2=0.9, Z-1=0.95, Z+1=1.05$ and $Z+2=1.1$. The car body of the head car was kept unchanged, and only the front window height of nose changed from the concave to a convex shape.

\subsection{Numerical Method and Settings}

In order to better meet the requirements of the grid resolution of the turbulence model chosen, a 1:25 scaled model was used in the computational analysis. The three-dimensional incompressible unsteady Reynolds averaged Navier-Stokes (URANS) equations and the SST $\mathrm{k}-\omega$ turbulence models [8] were used in this study. The commercial software package Fluent was used, and the governing equations were discretised by the finite volume method (FVM). The convection and diffusion terms were discretised by the second-order upwind scheme, and the time derivative was discretized by the second-order implicit scheme for unsteady flow calculations. The velocity-pressure coupling and solution procedures were based on the Semi-Implicit Method for Pressure Linked Equations (SIMPLEC) algorithm [9]. The time-step, $\Delta \mathrm{t}$, was $1 \times 10^{-4} \mathrm{~s}$, and the data obtained was for a physical time of $3.0 \mathrm{~s}$. This time allowed the flow to pass over the width of the railway more than 20 times.

Figure 3 shows the computational domain and the boundary conditions used. The face BFGC was the velocity-inlet, the face AEHD was the zero pressure-outlet, the face $A B C D, E F G H$ and DCGH were set as symmetry wall, the ground, windbreak and the train were set as no-slip wall. Figure 4 shows the computation 


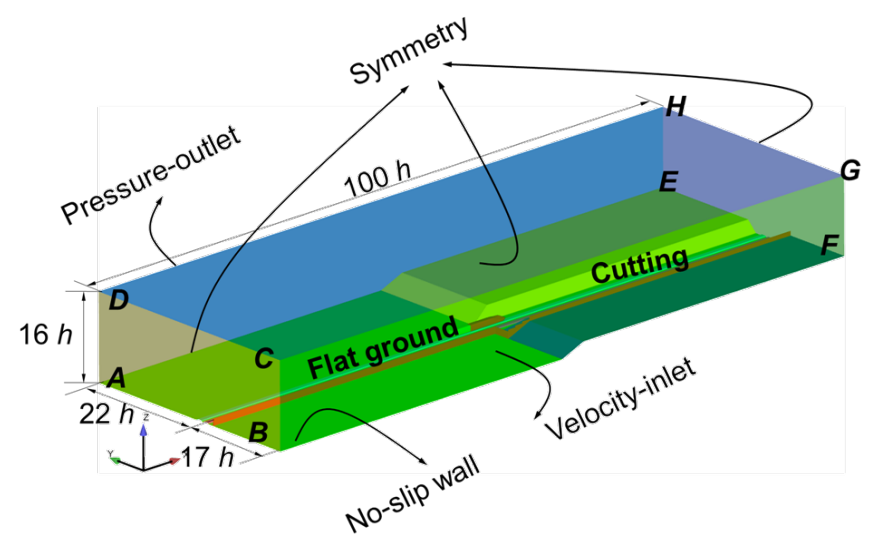

Figure 3. Computational domain and boundary conditions.
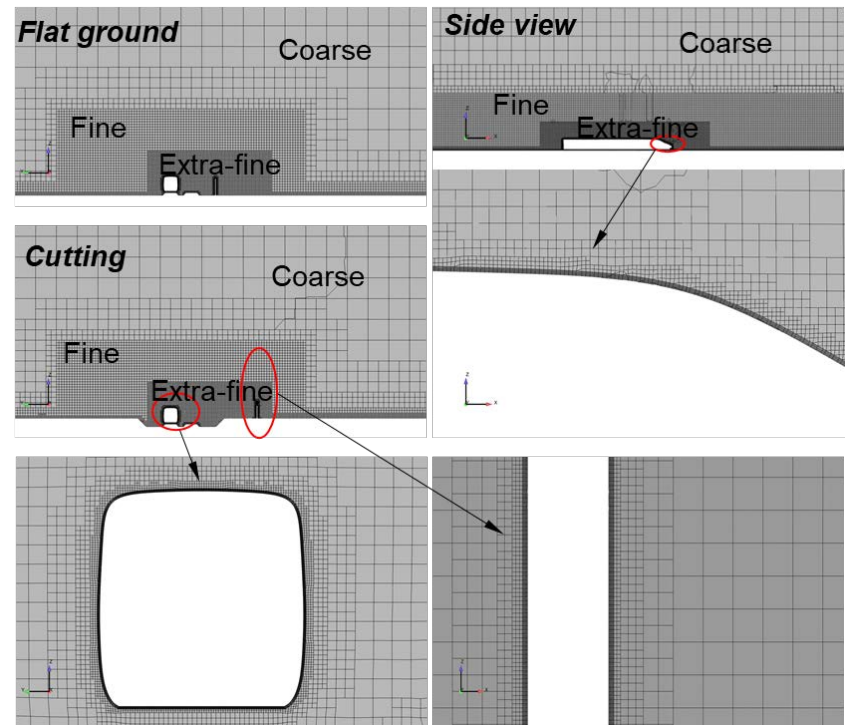

Figure 4. Computational mesh.

mesh around the train. The extra-fine mesh was around the train and followed by the fine mesh and coarse mesh. There were ten prism layers around the train and the windbreak wall to capture the velocity gradient change near the wall surface. The minimum mesh size is about $0.07 \mathrm{~mm}$, which makes the average $y^{+}$ around the model less than 10. According to the ANSYS Fluent Theory Guide [10], the $\omega$-equation can be integrated through the viscous sublayer by using a $y^{+}$-insensitive wall treatment, which blends the viscous sublayer formulation and the logarithmic layer formulation based on $y^{+}$. This formulation is the default for all $\omega$-equation based models. The enhanced wall treatment (EWT) was used in this paper to find the shear stress at the first cell close to the wall. This way, the calculations in this paper were feasible.

\section{Results and Discussions}

\subsection{Aerodynamic Forces}

The side force coefficient, $C_{y}$, the lift force coefficient, $C_{z}$, and the rolling 
moment coefficient, $C_{m x}$, are discussed in this section. In Equation (1), $F_{y}$, $F_{z}, M_{x}$ are the side force, lift force and roll moment, respectively. The air density, $\rho$, is $1.225 \mathrm{~kg} / \mathrm{m}^{3}$, and the wind speed, $u$, is $35 \mathrm{~m} / \mathrm{s}$. The reference area, $A$, is the full-scale cross-sectional area and is taken as $11.22 \mathrm{~m}^{2}$ and $l$ is the reference length, which is $3 \mathrm{~m}$ for a full-scale train. $C_{p}$ is the pressure coefficient, $p$ is the static pressure on the train surface, and $p_{0}$ is the reference pressure, which is 0 pa.

$$
C_{y}=\frac{F_{y}}{\frac{1}{2} \rho u^{2} A}, C_{z}=\frac{F_{z}}{\frac{1}{2} \rho u^{2} A}, C_{m x}=\frac{M_{x}}{\frac{1}{2} \rho u^{2} A l}, C_{p}=\frac{p-p_{0}}{\frac{1}{2} \rho u^{2}}
$$

Figure 5 shows the aerodynamic coefficients of side force $C_{y}$, lift force $C_{z}$ and rolling moment $C_{m x}$ for the head car. When the height of the front window increased, the $C_{y}$ and $C_{m x}$ increased by $26 \%$ and $27 \%$, respectively; for $C_{z}$, there was no noticeable increase or decrease trend with the change of nose shape. It only changed from positive value to negative value and the variation range of $C_{z}$ was $-0.08 \sim 0.04$, which was smaller when compared to those of $C_{y}$ and $C_{m x}$.

\subsection{Flow Structures}

Figure 6 shows the velocity streamlines around the nose region, which is selected to explain the variation of aerodynamic forces among different nose shapes. At $\mathrm{x} / \mathrm{h}=0.67$, the cross-section is higher than the position of the front window, and here the cross-section of $Z-2$ and $Z+2$ remain the same. Therefore, the flow structures between $Z-2$ and $Z+2$ are similar. But at the front window position $x h=1.76$, as shown in region $A$, the airflow above $Z-2$ flows smoother than that of $Z+2$. Therefore, it results in lower side force of $Z-2$. Besides, for the shape of $Z+2$, due to the significant positive pressure generated by the airflow in region $A$, the lift force changes from smaller positive value of $Z-2$ to the smaller negative value of $Z+2$, as shown in Figure 5 .

For a more intuitively view, Figure 7 shows the surface pressure distribution of the train. Except for the streamlined head region, the difference of pressure

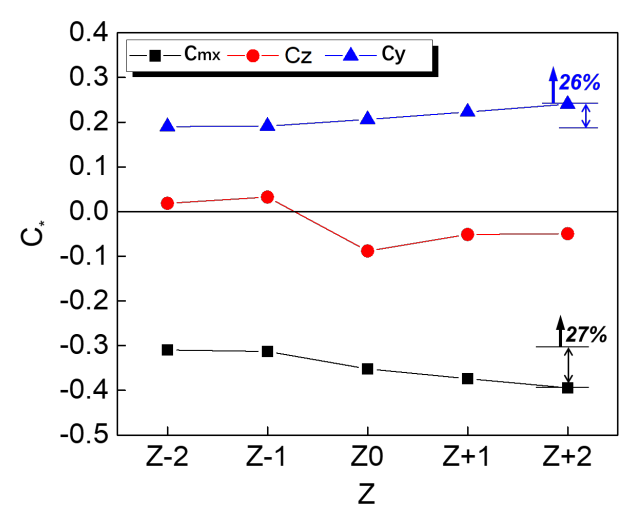

Figure 5. The variation of the aerodynamic coefficients with the dimensionless heights of the front window. 

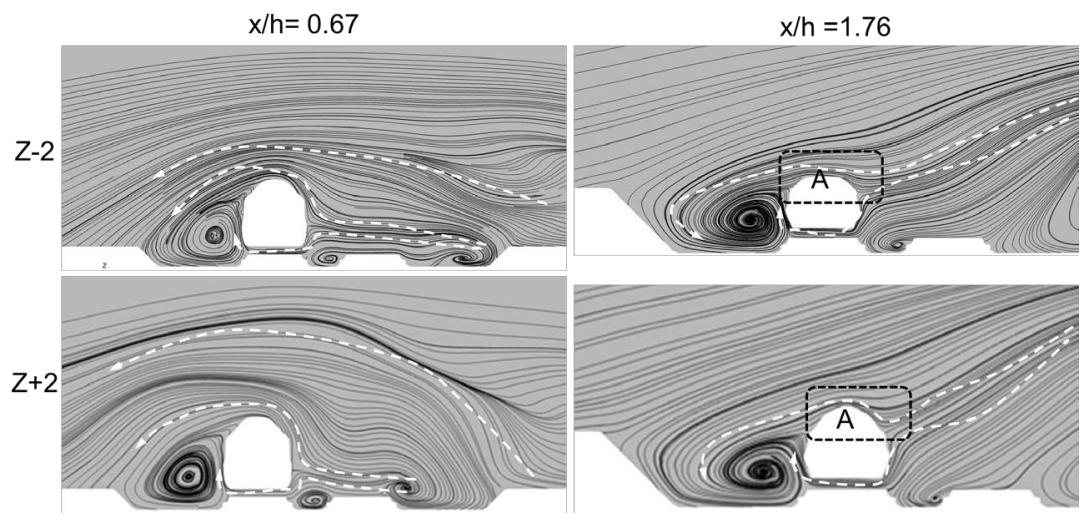

Figure 6. Flow structures around the train.

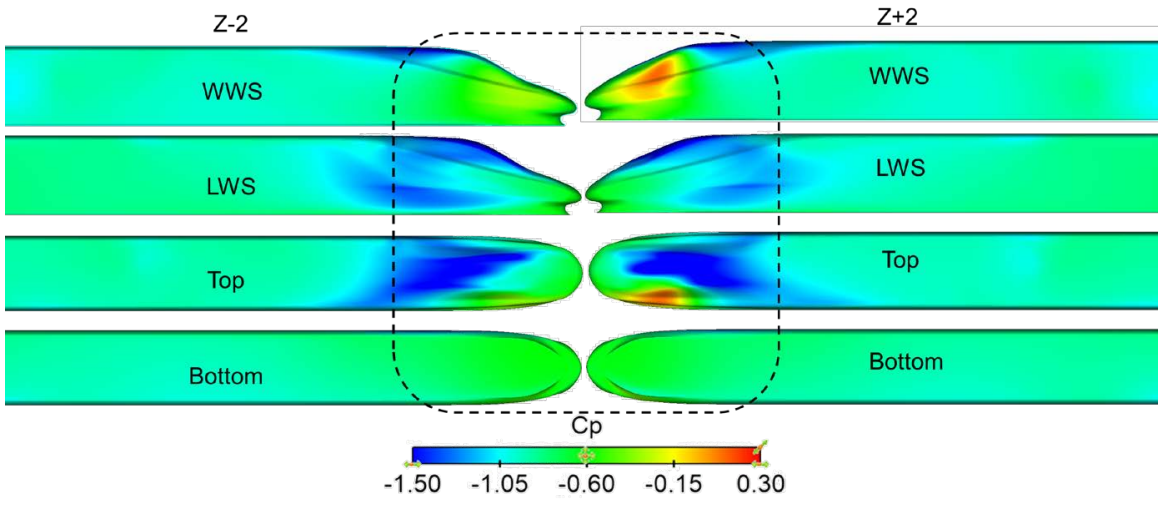

Figure 7. The pressure distribution on the train surface (WWS: Windward side, LWS: Leeward side).

distribution between $\mathrm{Z}-2$ and $\mathrm{Z}+2$ was slight. In the WWS of the streamlined head region, the higher window height of $Z+2$ induced larger positive pressure on the nose region, and it resulted in the more significant side force of $Z+2$. Compared the pressure distribution of top and bottom, in term of the shape of $Z$ -2 , the pressure of bottom was larger than that of top obviously, so the lift force was positive; but for $Z+2$, due to the impact of positive pressure on the top of streamlined head region, the lift force changed to be a slightly negative value.

\section{Acknowledgements}

This work was supported by the National Key R \& D Program of China (2016YFB1200504).

\section{Conflicts of Interest}

The authors declare no conflicts of interest regarding the publication of this paper.

\section{References}

[1] Baker, C.J. (2010) The Simulation of Unsteady Aerodynamic cross Wind Forces on Trains. Journal of Wind Engineering and Industrial Aerodynamics, 98, 88-99. 
https://doi.org/10.1016/j.jweia.2009.09.006

[2] Xu, J., Chen, Z.W. and Liu, T.H. (2019) Experimental and Numerical Research on the Safety of an EMU Running on a Normal-Speed Railway Line under Strong Wind. In IOP Conference Series: Materials Science and Engineering, IOP Publishing, Vol. 688, 044049. https://doi.org/10.1088/1757-899X/688/4/044049

[3] Yang, W., Deng, E., Lei, M., Zhu, Z. and Zhang, P. (2019) Transient Aerodynamic Performance of High-Speed Trains When Passing through Two Windproof Facilities under Crosswinds: A Comparative Study. Engineering Structures, 188, 729-744. https://doi.org/10.1016/j.engstruct.2019.03.070

[4] Hashmi, S.A., Hemida, H. and Soper, D. (2019) Wind Tunnel Testing on a Train Model Subjected to Crosswinds with Different Windbreak Walls. Journal of Wind Engineering and Industrial Aerodynamics, 195, 104013.

https://doi.org/10.1016/j.jweia.2019.104013

[5] Liu, T.H., Chen, Z.W., Zhou, X.S. and Zhang, J. (2018) A CFD Analysis of the Aerodynamics of a High-Speed Train Passing through a Windbreak Transition under Crosswind. Engineering Applications of Computational Fluid Mechanics, 12, 137-151. https://doi.org/10.1080/19942060.2017.1360211

[6] Chen, Z.W., Liu, T.H., Lu, Z.J., Liu, D.R. and Zhou, X.S. (2016) Study on the Vibration Offset of High-Speed Train Passing by a Windbreak Transition Section under Strong Wind in Lanzhou-Xinjiang Railway Lines. National Conference of Environmental Wind Engineering, Xining, 2016.

[7] Chen, Z.W., Liu, T.H., Li, M., Yu, M., Lu, Z. and Liu, D. (2019) Dynamic Response of Railway Vehicles under Unsteady Aerodynamic Forces Caused by Local Landforms. Wind and Structures, 29, 149-161.

[8] Menter, F.R. (1994) Two-Equation Eddy-Viscosity Turbulence Models for Engineering Applications. AIAA Journal, 32, 1598-1605. https://doi.org/10.2514/3.12149

[9] Van Doormaal, J.P. and Raithby, G.D. (1984) Enhancements of the SIMPLE Method for Predicting Incompressible Fluid Flows. Numerical Heat Transfer, 7, 147-163. https://doi.org/10.1080/01495728408961817

[10] ANSYS, I. (2013) ANSYS Fluent Theory Guide (Release 15.0). 